\title{
Sexual Decision-Making in HIV-Positive Men Who Have Sex with Men: How Moral Concerns and Sexual Motives Guide Intended Condom Use with Steady and Casual Sex Partners
}

\author{
Nicole M. C. van Kesteren • Harm J. Hospers • \\ Pepijn van Empelen • Gerard van Breukelen • \\ Gerjo Kok
}

Received: 15 August 2005 / Revised: 16 August 2006 / Accepted: 16 August 2006 / Published online: 27 February 2007

(C) Springer Science+Business Media, LLC 2007

\begin{abstract}
Determinants of intended condom use with steady and casual sex partners were examined among Dutch HIVpositive men who have sex with men (MSM) $(N=296)$. Given the proposition that safer sex behavior among HIVpositive people is a form of prosocial behavior, the present study extended the general framework of the Theory of Planned Behavior with Schwartz's norm-activation theory and tested the assumption that personal norms would mediate the effects of other psychosocial factors on intended condom use for anal sex. In addition, it was hypothesized that, depending on the context in which sex occurs, specific motives for unprotected anal sex may have a negative influence on intended condom use and, as such, undermine a prosocial tendency to practice safer sex. Therefore, we also investigated the influence of sexual motives for unprotected anal sex on intended condom use with steady and casual sex partners. Results indicated that the Theory of Planned Behavior adequately predicted condom use intentions (for
\end{abstract}

\author{
N. M. C. van Kesteren · H. J. Hospers · G. Kok \\ Center for Research on HIV/AIDS Prevention \\ and Education, Department of Experimental Psychology, \\ Maastricht University, \\ Maastricht, The Netherlands \\ P. van Empelen \\ Department of Clinical and Health Psychology, \\ Leiden University, \\ Leiden, The Netherlands \\ G. van Breukelen \\ Department of Methodology and Statistics, Maastricht University, \\ Maastricht, The Netherlands
}

N. M. C. van Kesteren $(\square)$

Department of Experimental Psychology, Maastricht University,

P.O. Box 616, 6200 MD Maastricht, The Netherlands

e-mail: n.vankesteren@psychology.unimaas.nl casual sex partners and steady sex partners, the explained variance was $52 \%$ and $53 \%$, respectively). However, our proposed model of sexual decision-making significantly improved the prediction of behavioral intentions. For steady and casual sex partners, the assumption of the mediating role of personal norms on condom use intention was confirmed empirically. Additionally, sexual motives for unprotected anal sex exerted, as expected, a direct, negative effect on condom use intention with casual sex partners. The implications of the findings for future research and the development of HIV-prevention programs for HIV-positive MSM are discussed.

Keywords HIV-positive - Men who have Sex with Men . Sexual risk behavior $\cdot$ Personal norms $\cdot$ Sexual motives

\section{Introduction}

Studies on the effects of HIV counseling and testing show that most individuals who are tested HIV-positive respond by reducing their sexual risk behavior (Weinhardt, Carey, Johnson, \& Bickman, 1999). Nevertheless, it has been found that approximately one third of HIV-positive men who have sex with men (MSM) engaged in unprotected anal sex in the last two to three months (for a review, see Kalichman, 2000). Moreover, increased prevalence rates of gonorrhea and syphilis have been reported among HIV-positive and HIV-negative MSM in several western regions (e.g., Anon, 2002; Macdonald et al., 2004; Van de Laar \& Op de Coul, 2003). These findings suggest a rise in unprotected anal sex among HIV-negative and HIV-positive MSM. Given that at least a subgroup of HIV-positive MSM, for various reasons, engage in risky sexual behavior, an understanding of why 
this occurs remains a matter of significant public healthy concern.

Studies have been conducted that examined possible antecedents of (un)safe sexual behavior in HIV-positive MSM (Crepaz \& Marks, 2002). One of the factors that has been identified as promoting sexual behavior change is perception of risk, i.e., awareness that unprotected sex increases the risk for HIV infection and STDs. Accordingly, studies have indicated that HIV-positive MSM who believe that HIVsuperinfection and other STDs may have negative consequences for their own health are more likely to use condoms for anal sex (Colfax et al., 2004; McConnell, Grant, $\&$ Greenwood, 2002). However, other studies suggest that a person's own risk of HIV-superinfection and STDs is not a key concern. Of great importance is the finding that safer sex in HIV-positive MSM is primarily motivated by concerns about the risks for the other and that concerns about one's own risks are subordinate (Keogh, Weatherburn, \& Stephens, 1999; Van Kesteren, Hospers, Kok, \& Van Empelen, 2005).

The notion that HIV-positive MSM engage in safer sex because of concerns about the welfare of sex partners can be characterized as a form of prosocial behavior. Prosocial behavior "represents a broad category of acts ... that are defined as generally beneficial to other people" (Penner, Dovidio, Piliavin, \& Schoeder, 2005, p. 366). If HIV-positive MSM indeed engage in safer sex to benefit others, or more specifically, are motivated to prevent harm to others, it is of particular importance to understand why this is the case and to determine which factors promote such behavior. The literature offers several explanations to account for prosocial behavior. One explanation for a wide range of moral and prosocial behaviors, which has received considerable attention, is the so-called personal standards approach (e.g., Manstead, 2000). This approach emphasizes how internalized, self-reinforced standards, such as altruism, can promote prosocial behavior as people strive to maintain a positive self-image or achieve their ideals (Penner et al., 2005).

Indeed, some qualitative studies suggest that internalized values or personal standards play an important role in the practice of safer sexual behavior. For example, Nimmons and Folkman (1999) showed that HIV-positive MSM described moral and altruistic values in regard to the need to practice safer sex. A study by Wolitski, Bailey, O'Leary, Gómez, and Parsons (2003) found that many HIV-positive MSM perceived that they had a particular responsibility for protecting their partners and that this perception influenced safer sexual decision-making. Participants cited altruism and self-imposed standards as the motivations underlying their beliefs about personal responsibility. Similarly, Van Kesteren et al. (2005) found that a greater concern about potential HIV transmission to sex partners was related to enhanced feelings of personal responsibility for safer sex.
While these studies have contributed greatly to a preliminary understanding of the role of intrinsic motivation in safer sexual behavior, the factors that may motivate HIV-positive MSM to adopt safer sex practices for the protection of others warrants further examination. This study represents such an attempt, examining social-psychological factors of condom use in the context of steady and casual sex. For this reason, we combined the Theory of Planned Behavior (Ajzen, 1991), a well-established framework used to understand behavior in a broad range of contexts, with the norm-activation theory (Schwartz, 1977; Schwartz \& Howard, 1981), a framework specifically developed to understand prosocial behavior. In spite of the supposed importance of prosocial motivation in safer sexual behavior, it is possible that other motivations (e.g., sexual motives) for unprotected anal sex may have a negative influence on intended condom use in certain circumstances (Cooper, Shapiro, \& Powers, 1998). Therefore, for both steady and casual sex partners, we examined the extent to which sexual motives for unprotected anal sex negatively affect intended condom use.

\section{Theory of Planned Behavior}

The Theory of Planned Behavior (TPB) (Ajzen, 1991) is one of the most important social psychological theories for predicting and understanding behavior. The TPB posits that the most proximal determinant of whether or not a person performs a behavior is his intention to do so. According to the theory, behavioral intention is determined by attitude, subjective norm, and perceived behavioral control. Attitude is the person's overall evaluation of the advantages and disadvantages of a particular behavior whereas subjective norms are determined by the perceived social pressure to perform the behavior. Perceived behavioral control is the person's conviction about whether or not the required skills and resources to perform the behavior are at his disposal and is closely related to Bandura's (1986) concept of self-efficacy. The TPB has received significant support from research on the adoption of many health-related behaviors (Godin \& Kok, 1996), including safer sex behavior (Albarracín, Fishbein, Johnson, \& Muellerleile, 2001; Rye, Fisher, \& Fisher, 2001; Sheeran, Abraham, \& Orbell, 1999).

Essentially, the TPB stresses the importance of cognitive, information processing mechanisms in explaining behavior. However, not every act of safer sex is necessarily the result of deliberate thought processes. Of particular interest are the growing number of studies that suggest that HIV-positive MSM are motivated by concerns about the effect that their sexual behavior may have on others; that is, that they feel personally responsible for protecting their partners from HIV. Although we agree that the TPB provides a valuable framework for predicting safer sex practices, we argue that this perspective is too narrow and may not fully account for 
feelings of personal responsibility that may promote safer sexual behavior. More specifically, we believe that safer sexual behavior in HIV-positive MSM is based on concerns that go beyond a purely rational weighing of personal advantages and disadvantages, i.e., that safer sex is simply the right thing to do. One theory that may help explain why HIV-positive MSM are motivated to adopt safer sexual practices for the protection of others is Schwartz' (1977) normactivation theory.

\section{Norm-Activation Theory}

The norm-activation theory (Schwartz, 1977; Schwartz \& Howard, 1981) seeks to predict and understand prosocial or altruistic behavior. According to norm-activation theory, personal norms are the immediate determinant of behavior. Personal norms are considered as strong intrinsic motivators, as they trigger an individual's internal value system and are tied to one's self-concept. In the case of sexual behavior, these aspects reflect the feeling of moral obligation to practice safer sex because of concern about the welfare of sex partners. That personal norms may play an important role in safer sexual behavior in HIV-positive MSM was shown in a study by Godin, Savard, Kok, Fortin, and Boyer (1996). Their study showed that personal norms, in addition to perceived behavioral control, are important predictors of intended condom use for anal sex.

The important relationship between personal norms and condom use intention underscores the assumption that safer sexual behavior is influenced by feelings of moral obligation. However, Schwartz argued that there will be no moral motivation unless: (1) an individual is aware of the specific action that is needed and the consequences of action or inaction to oneself and others (awareness of need); (2) an individual ascribes responsibility to himself for the consequences of the action or inaction (ascription of responsibility); (3) a person identifies actions that might be effective in handling the specific situation (efficacy); and (4) a person believes that he is capable of performing the required actions or behavior (ability). As such, we expect that, in predicting safer sex, awareness of need and ascription of responsibility may be important determinants of behavioral intention to use condoms for anal sex with steady and casual sex partners. Note that in this context, efficacy and ability are not differentiated because both concepts seem to be covered by the theoretical paradigm of the TPB (i.e., attitude and self-efficacy, respectively).

Sexual motives for unprotected anal sex

Notwithstanding our argument that personal norms play a central role in sexual decision-making, we expect that, depending on the social context in which sex occurs, strong motives to engage in unprotected sex may conflict with one's personal norm for safer sex. For instance, Cooper et al. (1998) have demonstrated that sexual behaviors, whether risky or safe, may serve a range of psychological functions that have little to do with health protection and disease avoidance. Indeed, the study by Van Kesteren et al. (2005) indicated that the extent to which HIV-positive MSM acted in accordance with their feelings of personal responsibility to practice safer sex depended, in part, on their sexual motives for engaging in unprotected anal sex. Typically, HIV-positive MSM reported having engaged in unprotected anal sex to express emotions related to love or because they were "sexually turned-on" by their sex partners. Thus, sexual motives appear to have a negative influence on intended condom use, which may undermine a prosocial motivation to practice safer sex. However, it can be argued that a conflict such as this may play a role more in casual sex encounters than in steady sexual relationships, as it is likely that the benefits of unprotected sex are more salient in the context of casual sex (i.e., when one does not necessarily know one's sex partner and is less likely to be confronted with the potential adverse longer term social consequences of having engaged in unprotected sex) than with steady partners (i.e., when one is emotionally involved with a partner and committed to an ongoing relationship) (Flowers, Marriott, \& Hart, 2000; Van Kesteren et al., 2005). It has been shown that when people perceive increased benefits of a specific behavior (unsafe sex), it leads to a more favorable affective impression, resulting in lower judgments of risk (so-called affect-heuristic; Finucane, Alhakami, Slovic, \& Johnson, 2000). Therefore, we expect that sexual motives may have a negative impact on intended condom use, particularly in casual sex encounters.

\section{Proposed model of sexual decision-making}

Safer sex in HIV-positive MSM can be seen as a prosocial behavior, making it vital to integrate variables specific to the TPB with variables specific to the norm-activation theory. In accordance with the TPB, we propose a model (see Fig. 1) in which intention is the most proximal determinant of behavior. However, in line with the norm-activation theory, we assume that the decision to use condoms for anal sex largely depends on one's intrinsic motivation to engage in safer sex. Accordingly, we expect personal norms to be the most direct determinant of intention, thereby mediating the effects of the other determinants specific to the TPB and the norm-activation theory. Following Cooper et al. (1998), we further assume that sexual motives for unprotected anal sex may have a direct and negative impact on intended condom use and, as such, may compete with a prosocial tendency to engage in safer sex. However, due to the social context in which sex occurs, we hypothesize that sexual motives will contribute to the explanation of intended condom use with 


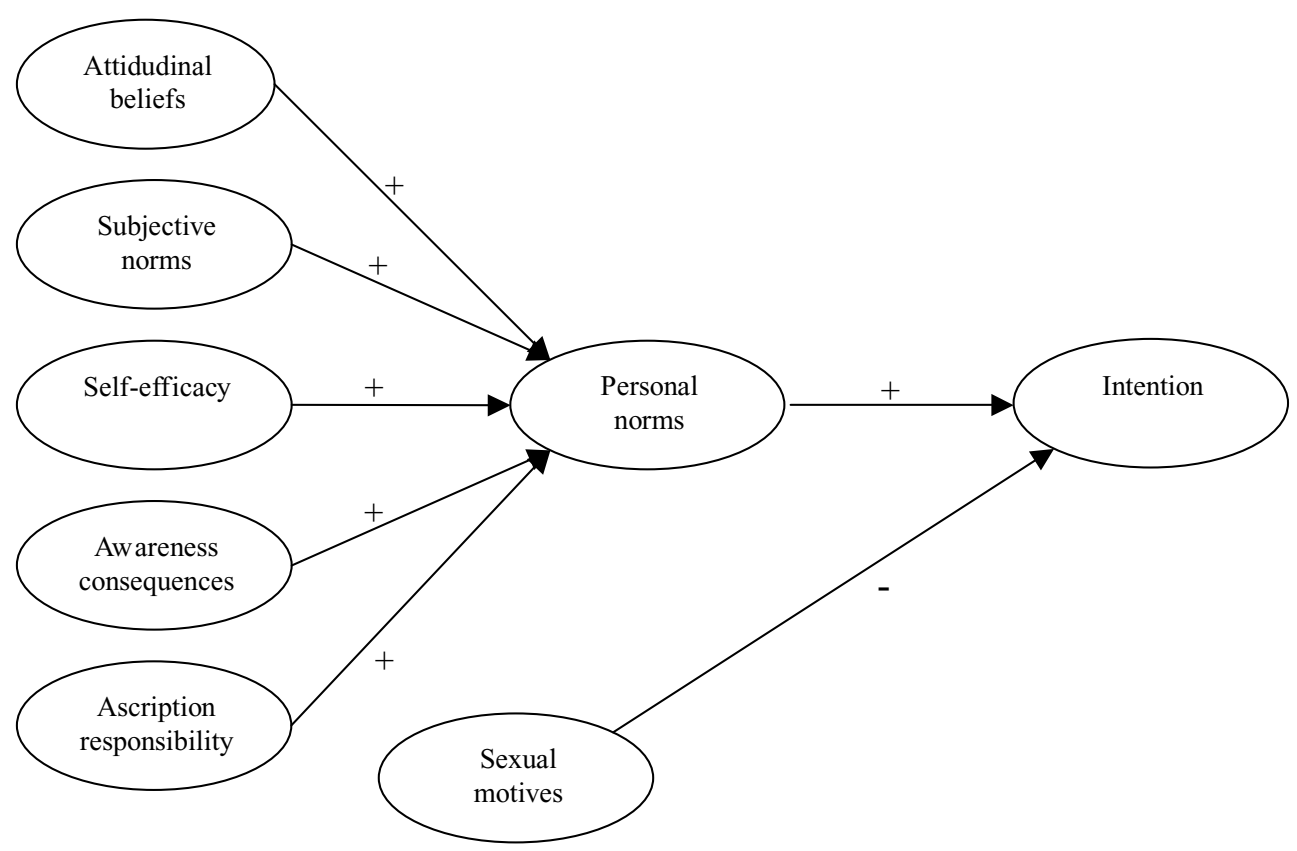

Fig. 1 Proposed model of sexual decision-making

casual sex partners, whereas this is unlikely to be the case in the context of steady sex partners.

\section{Method}

Participants

Data were obtained by means of a self-administered questionnaire between July 2002 and April 2003. Participants were recruited through AIDS consultants working in 15 Dutch hospitals. Participants were asked to fill out the questionnaire at home and return the questionnaires directly to the research institution by means of a stamped, pre-addressed envelope. Consequently, no information was available about the response rate per hospital. Participation was on a voluntary and anonymous basis. A pilot study indicated that completion of the questionnaire took about 30 to $45 \mathrm{~min}$. Participants received no compensation for filling out the questionnaires. Approval for the study was obtained from the Ethics Committee of Maastricht University Hospital.

Participants who met the following criteria were included in the study: (1) tested positive for HIV-antibodies; (2) identified themselves as homosexual or bisexual; (3) aged between 20 and 65 years; and (4) were sufficiently fluent in Dutch to complete the questionnaire. A total of 1,050 questionnaires were distributed, of which 296 were completed and returned (response rate $=28.2 \%$ ).

Table 1 summarizes the demographic characteristics of the participants. Participants were predominantly Dutch nationals, were mainly from the Western part of the Netherlands, including Amsterdam, and ranged in age from 25 to 59 years, with a mean age of 42.1 years. Most participants had a medium or high level of education and were employed fulltime or part-time. Most participants identified themselves as exclusively homosexual. More than half of the men had known themselves to be HIV-positive for 6 years or less. The majority of men was aware of their CD4 counts and viral load and indicated that they were currently on some form of HIV antiretroviral therapy.

\section{Measures}

The questionnaire was based on earlier studies (Hogeweg \& Hospers, 2000; van Kesteren et al., 2005) and consisted of several questions on determinants for explaining condom use behavior: attitudinal beliefs, subjective norms, self-efficacy, personal norms, awareness of consequences, ascription of responsibility, sexual motives, intention and demographic variables. Separate scales were used for condom use with steady and casual sex partners for all determinants. The questionnaire was pre-tested among a group of $12 \mathrm{HIV}$-positive MSM for comprehension and completeness.

Attitudinal beliefs were measured through 16 items drawn from interviews with HIV-positive MSM (van Kesteren et al., 2005) and from an earlier quantitative study among MSM (Hogeweg \& Hospers, 2000). Four items were used to assess response efficacy (e.g., "By using condoms when having anal intercourse, I protect my steady partner/casual sex partners against the AIDS virus/HIV-superinfection"). In addition, seven possible pros (e.g., "By using condoms during anal sex with my steady partner/casual sex partners, I worry less about 
Table 1 Sociodemographic characteristics of the sample (maximum $N=296)$

\begin{tabular}{|c|c|c|}
\hline Characteristics & $N$ & $\%$ \\
\hline \multicolumn{3}{|l|}{ Nationality } \\
\hline Dutch & 251 & 85.7 \\
\hline Surinam/Antillean & 5 & 1.7 \\
\hline Other & 37 & 12.6 \\
\hline \multicolumn{3}{|l|}{ Geographic area of the Netherlands } \\
\hline Amsterdam & 73 & 25.3 \\
\hline West (excluding Amsterdam) & 110 & 38.0 \\
\hline South & 67 & 23.2 \\
\hline Northeast & 39 & 13.5 \\
\hline \multicolumn{3}{|l|}{ Age } \\
\hline $25-35$ & 55 & 18.9 \\
\hline $36-45$ & 136 & 46.7 \\
\hline $46-55$ & 82 & 28.2 \\
\hline$>56$ & 18 & 6.2 \\
\hline \multicolumn{3}{|l|}{ Education } \\
\hline Higher vocational education or university & 124 & 43.1 \\
\hline Secondary vocational training or high school & 120 & 41.7 \\
\hline Primary school or basic vocational training & 34 & 11.8 \\
\hline Other & 10 & 3.5 \\
\hline \multicolumn{3}{|l|}{ Employment status } \\
\hline Full-time & 117 & 43.5 \\
\hline Part-time & 80 & 29.7 \\
\hline Unemployed & 72 & 26.8 \\
\hline \multicolumn{3}{|l|}{ Self-identification } \\
\hline Homosexual & 244 & 82.4 \\
\hline More homosexual than heterosexual & 38 & 12.8 \\
\hline Bisexual & 8 & 2.7 \\
\hline More heterosexual than bisexual & 4 & 1.4 \\
\hline Other & 2 & 0.7 \\
\hline \multicolumn{3}{|l|}{ Years knowing HIV-positive status } \\
\hline$<2 \mathrm{yrs}$ & 59 & 20.1 \\
\hline $2-6$ yrs & 116 & 39.6 \\
\hline $7-11$ yrs & 71 & 24.2 \\
\hline $12-16$ yrs & 37 & 12.6 \\
\hline$>16 \mathrm{yrs}$ & 10 & 3.4 \\
\hline \multicolumn{3}{|l|}{ Self-reported CD4+ } \\
\hline$<200$ & 33 & 11.1 \\
\hline $200-500$ & 120 & 40.5 \\
\hline$>500$ & 92 & 31.1 \\
\hline Don’t know & 51 & 17.2 \\
\hline \multicolumn{3}{|l|}{ Self-reported viral load } \\
\hline Detectable [median $=10.000$, range 50-2.080.000] & 72 & 25.9 \\
\hline Undetectable & 176 & 63.3 \\
\hline Don’t know & 30 & 10.8 \\
\hline \multicolumn{3}{|l|}{ Antiviral treatment } \\
\hline No & 59 & 20.1 \\
\hline Yes & 234 & 79.9 \\
\hline
\end{tabular}

his/their well-being"), and five possible cons of condom use behavior (e.g., "Using condoms for anal sex with my steady partner/casual sex partners reminds me of HIV/AIDS") were included in the questionnaire. Items were indexed on 5-point scales $(1=$ totally disagree, $5=$ totally agree $)$, and had an alpha of .81 for steady and .76 for casual sex partners.
Subjective norms were measured through the use of three items on 5-point scales. Two items assessed the perception of participants of the opinions of other important people on whether or not they should use condoms when having anal intercourse $(1=$ certainly not, $5=$ certainly). Following Schwartz (1973), one item assessed perceived social sanctions regarding not using condoms during anal intercourse and was expressed as follows: "How do you think important others would react if you told them that you don't use condoms when having anal intercourse with your steady partner/casual sex partners?" $(1=$ very approving, $5=$ very disapproving). Alpha for steady and casual sex partners was. 76 and .63, respectively.

Self-efficacy was measured with seven items based on van Kesteren et al. (2005) and Hogeweg and Hospers (2000) (e.g., "Suppose you want to use condoms when having anal intercourse, will you be able to discuss condom use with your steady partner/casual sex partners?"). Items were measured on 5-point scales ( $1=$ certainly not, $5=$ certainly), and had an alpha of .89 for steady and .87 for casual sex partners.

Personal norms were measured by means of three items on 5-point scales (Godin et al., 1996; Parker, West, Stradling, \& Manstead, 1995), such as: "As a matter of principle, I use condoms every time I have anal intercourse with my steady partner/casual partners." Items were rated on 5-point scales $(1=$ totally disagree, $5=$ totally agree $)$ and had an alpha of .96 and .90 for steady and casual sex partners, respectively.

Both awareness of consequences for self and awareness of consequences for others were assessed separately for condom use with steady and casual sex partners by a single item on a 5 -point $(1=$ totally agree, $5=$ totally disagree) scale. Awareness of consequences for self measured the participant's view about whether the consequences for his health were negligible when not using condoms during anal sex. Awareness of consequences for others measured the participant's views about whether the consequences for the health of his partner were negligible when not using condoms during anal sex.

Ascription of responsibility to self was measured by means of four items on 5-point scales concerning responsibility for condom use behavior and one item concerning transmission of HIV. For example: "How responsible are you yourself for negotiating condom use?" ( $1=$ not at all, $5=$ completely $)$. Alpha for steady and casual sex partners was .91 and .89, respectively.

Sexual motives for unprotected anal sex were measured using seven affective states on 7-point scales $(1=$ considerably less, $7=$ considerably more), such as lust, love, excitement, and feeling good. Following Nelissen, Dijker, and De Vries (in press), participants were asked to indicate the extent to which they would feel a particular emotion when engaging in unprotected anal sex with steady (alpha $=.89)$ and casual sex partners (alpha $=.85$ ). 
Intention to use condoms when having anal intercourse was measure by the following three items on 5-point scales: "I intend to use a condom when having anal intercourse with my steady partner/casual partners"; "I will try to use a condom when ..."; and "I plan to use a condom when..." $(1=$ certainly not, $5=$ certainly). Alpha for both steady and casual sex partners was .93.

With respect to sexual risk behavior, participants were asked whether or not they had engaged in receptive and insertive oral sex with ejaculation and in receptive and insertive anal sex in the past six months (separate for steady and casual sex partners). For each sexual behavior they had engaged in, the frequency of condom use $(1=$ never, $5=$ always $)$ was assessed.

\section{Results}

Sexual behavior

Table 2 shows that about $60 \%$ of the participants reported a male steady partner in the preceding six months. Among these, about one third (30.3\%) reported that they had not had oral or anal sex with their steady partner. Among those who had had oral sex with ejaculation with their steady partners $(23.6 \%)$, only one person reported that he consistently had used a condom. Among those who had had anal sex with their steady sex partners $(51.1 \%)$, about half $(48.4 \%)$ reported that they had not used condoms consistently. Approximately $72 \%$ of the participants reported male casual sex partners in the preceding six months. When oral intercourse was considered, none of the men who had engaged in oral sex with ejaculation (31.8\%) reported consistent condom use. When anal sex was considered, about half $(45.6 \%)$ of the participants who had engaged in anal intercourse with casual sex partners $(74.8 \%)$ had not consistently used condoms.

Among men who had anal sex with their steady sex partner, unprotected sex occurred more often within the context of HIV-seroconcordant relationships than within HIVserodiscordant relationships: $23.3 \%$ (7 out of 30) of the men with an HIV-positive partner reported consistent condom use in the preceding six months compared to $61.0 \%$ (25 out of 41) of the men with an HIV-negative partner and 73.7\% (14 out of 19) of the men with a partner whose HIV status was unknown, $\chi^{2}(2)=14.7, p<.01$.

Although no data were available on the HIV-status of casual sex partners, participants were asked two questions regarding disclosure of HIV-status. The majority of the participants $(82.8 \%)$ reported that they never or rarely had informed casual sex partners about their HIV-status in the preceding six months. Similarly, most participants $(88.3 \%)$ reported that casual sex partners had never or rarely informed them of their HIV-status (see Table 2). Thus, accurate
Table 2 Descriptives of sexual behavior and disclosure in casual sex encounters of the sample HIV-positive MSM $(N=296)$

\begin{tabular}{|c|c|c|}
\hline & $N$ & $\%$ \\
\hline $\begin{array}{l}\text { Steady partner(s) in the preceding } \\
6 \text { months }\end{array}$ & 178 & 60.1 \\
\hline $\begin{array}{l}\text { Anal or oral sex with steady sex } \\
\text { partner }\end{array}$ & $124(178)$ & 69.7 \\
\hline $\begin{array}{l}\text { Oral intercourse with ejaculation } \\
\text { with steady sex partner }\end{array}$ & 42 (178) & 23.6 \\
\hline $\begin{array}{l}\text { Unprotected oral intercourse } \\
\text { with steady sex partner }\end{array}$ & $41(42)$ & 97.6 \\
\hline $\begin{array}{l}\text { Anal intercourse with steady sex } \\
\text { partner }\end{array}$ & $91(178)$ & 51.1 \\
\hline $\begin{array}{l}\text { Unprotected anal intercourse with } \\
\text { steady sex partner }\end{array}$ & $44(91)$ & 48.4 \\
\hline $\begin{array}{l}\text { Casual partner(s) in the preceding } \\
\qquad 6 \text { months }\end{array}$ & 214 & 72.3 \\
\hline $\begin{array}{l}\text { Anal or oral sex with casual sex } \\
\text { partners }\end{array}$ & $167(214)$ & 78.0 \\
\hline $\begin{array}{l}\text { Oral intercourse with ejaculation } \\
\text { with casual sex partners }\end{array}$ & 68 (214) & 31.8 \\
\hline $\begin{array}{l}\text { Unprotected oral intercourse } \\
\text { with casual sex partners }\end{array}$ & $68(68)$ & 100.0 \\
\hline $\begin{array}{l}\text { Anal intercourse with casual sex } \\
\text { partners }\end{array}$ & $160(214)$ & 74.8 \\
\hline $\begin{array}{l}\text { Unprotected anal intercourse with } \\
\text { casual sex partner }\end{array}$ & 73 (160) & 45.6 \\
\hline \multicolumn{3}{|l|}{$\begin{array}{l}\text { Disclosure of HIV status in casual } \\
\text { sex encounters }\end{array}$} \\
\hline $\begin{array}{l}\text { Has never/rarely informed } \\
\text { casual sex partners about } \\
\text { HIV-positive status }\end{array}$ & $177(214)$ & 82.8 \\
\hline $\begin{array}{l}\text { Was never/rarely informed about } \\
\text { HIV-status of casual sex partners }\end{array}$ & $189(214)$ & 88.3 \\
\hline
\end{tabular}

knowledge of each others HIV-status appears to be minimal, which makes the use of effective partner selection strategies (i.e., "serosorting") as an explanation for the occurrence of unprotected sex within casual sex encounters less likely.

\section{Descriptive statistics and correlations}

Means, $S D$ s, and correlations for the determinants of condom use for anal sex are provided in Table 3. A missing value analysis was conducted for independent variables relating to condom use with steady and casual sex partners. Participants with missing values exceeding $10 \%$ of all items were excluded from further data analyses. For participants with less than $10 \%$ missing values, the item score was replaced with the mean of the remaining participants for the respective item. As a result, analyses of intention to use condoms were conducted among 149 out of 178 participants who reported a steady sex partner and 188 out of 214 participants who reported casual sex partners in the preceding six 
Table 3 Means and correlations for determinants of condom use with steady ( $N=149$; below diagonal) and casual sex partners $(N=188$ above diagonal)

\begin{tabular}{|c|c|c|c|c|c|c|c|c|c|c|}
\hline Scale & Range & (1) & (2) & (3) & (4) & $(5)$ & (6) & (7) & (8) & (9) \\
\hline Intention (1) & $1-5$ & - & $.56^{* *}$ & $.57^{* *}$ & $.67^{* *}$ & $.83^{* *}$ & $.36^{* *}$ & $.25^{* *}$ & $.64^{* *}$ & $-.56^{* *}$ \\
\hline Attitudinal beliefs (2) & $1-5$ & $.60^{* *}$ & - & $.49^{* *}$ & $.48^{* *}$ & $.57^{* *}$ & $.28^{* *}$ & $.18^{*}$ & $.53^{* *}$ & $-.55^{* *}$ \\
\hline Subjective norms (3) & $1-5$ & $.77^{* *}$ & $.57^{* *}$ & - & $.45^{* *}$ & $.62^{* *}$ & $.17^{*}$ & .07 & $.45^{* *}$ & $-.43^{* *}$ \\
\hline Self-efficacy (4) & $1-5$ & $.74^{* *}$ & $.62^{* *}$ & $.69^{* *}$ & - & $.62^{* *}$ & $.36^{* *}$ & $.24^{* *}$ & $.56^{* *}$ & $-.49^{* *}$ \\
\hline Personal norms (5) & $1-5$ & $.88^{* *}$ & $.64^{* *}$ & $.80^{* *}$ & $.74^{* *}$ & - & $.32^{* *}$ & $.22^{* *}$ & $.64^{* *}$ & $-.53^{* *}$ \\
\hline Awareness consequences self (6) & $1-5$ & $.23^{*}$ & $.30^{* *}$ & $.21^{*}$ & $.26^{* *}$ & $.22^{* *}$ & - & $.72^{* *}$ & $.26^{* *}$ & $-.29^{* *}$ \\
\hline Awareness consequences others (7) & $1-5$ & $.39^{* *}$ & $.35^{* *}$ & $.38^{* *}$ & $.37^{* *}$ & $.41^{* *}$ & $.53^{* *}$ & - & $.23^{* *}$ & $-.23^{* *}$ \\
\hline Ascription of responsibility (8) & $1-5$ & $.60^{* *}$ & $.60^{* *}$ & $.51^{* *}$ & $.71^{* *}$ & $.60^{* *}$ & $.18^{*}$ & $.35^{* *}$ & - & $-.49^{* *}$ \\
\hline Sexual motives (9) & $1-7$ & $-.57^{* *}$ & $-.62^{* *}$ & $-.57^{* *}$ & $-.59^{* *}$ & $-.59^{* *}$ & $-.16^{*}$ & $-.31^{* *}$ & $-.47^{* *}$ & - \\
\hline \multicolumn{11}{|l|}{ Steady } \\
\hline$M$ & & 4.1 & 3.5 & 4.3 & 4.2 & 4.1 & 3.3 & 4.0 & 4.2 & 3.5 \\
\hline$S D$ & & 1.3 & 0.7 & 1.0 & 0.9 & 1.4 & 1.6 & 1.4 & 0.7 & 1.6 \\
\hline \multicolumn{11}{|l|}{ Casual } \\
\hline$M$ & & 4.3 & 3.8 & 4.3 & 4.2 & 4.3 & 3.8 & 4.2 & 4.3 & 3.4 \\
\hline$S D$ & & 1.1 & 0.6 & 0.6 & 0.8 & 1.1 & 1.2 & 1.2 & 0.8 & 1.4 \\
\hline
\end{tabular}

${ }^{*} p<.05$.

${ }^{* *} p<.01$.

months. Of the participants who were included in the analyses with steady and casual sex partners, there were 22 and 24 , respectively, who had one or more missing items (range $1-4)$. In both samples, however, the majority was missing only one of the questionnaire items.

The descriptive statistics indicates that, in general, participants' intentions to use condoms during anal sex with steady and casual sex partners were high. In addition, the means of most of the other determinants were on the positive side of the scale. The exception was for sexual motives for unprotected anal sex, where participants scored negative with regard to both steady and casual sex partners. Consistent with our proposed model (see Fig. 1), attitudinal beliefs, subjective norms, self-efficacy, personal norms awareness of consequences for self and others, and ascription of responsibility to self were all positively correlated with behavioral intention, with the exception of sexual motives for unprotected anal sex. As expected, the correlation between sexual motives for unprotected anal sex and intended condom use was negative for both steady and casual sex partners.

\section{Predictors of intended condom use}

Because intention for both steady and casual sex partners was positively skewed (more than $50 \%$ of the sample scored 5 on a 5-point scale), intended condom use with steady and casual sex partners was dichotomized on its median into high versus low intention. To test our proposed model (see Fig. 1), two hierarchical logistic regression analyses were conducted with intended condom use with steady and casual sex partners as the outcome variables. Personal characteristics and partner variables were controlled in both analyses and were entered first. In order to examine the relative contribution of the TPB variables (i.e., attitudinal beliefs, subjective norms and selfefficacy), these variables were entered in the second step. Awareness of consequences for self and others and ascription of responsibility were entered in the third step, followed by sexual motives for unprotected anal sex in the fourth step. Personal norms were entered in the final step of the regression analyses. In addition, we examined the mediating role of personal norms following the standard procedure specified by Baron and Kenny (1986).

Prior to analyses, collinearity between all variables in the regression analyses was checked by computing the Variance Inflation Factor (VIF) of each variable. Values above 10 were regarded as an indication of near-collinearity (Kleinbaum, Kupper, Muller, \& Nizam, 1998). With respect to steady and casual sex partner variables, all VIFs were $<5$ and $<3$, respectively. Additionally, initial regression analyses were conducted to minimize the number of potential personal characteristics and partner variables used in the logistic regression. Only those personal characteristics and partner variables making significant contributions to prediction of intended condom use with steady or casual sex partners were included in subsequent analyses.

\section{Steady sex partners}

First, a regression of intended condom use with steady sex partners on personal characteristics (age, education, antiviral treatment, and years knowing HIV-positive status) and partner variables (steady partner only versus casual partners 
as well and HIV-negative or unknown status partner versus HIV-positive status) showed education level and partner HIV status to be the only significant predictors. Therefore, these variables were entered in the first step of the subsequent regression analysis, yielding an explained variance of 13\% (see Table 4). When the TPB variables were entered in the second step, a further $40 \%(p<.001)$ of variance was explained, with self-efficacy as a significant predictor. Subjective norms were borderline significant ( $p=.05$ ). As shown in Table 4, there was no significant increase in variance explained with the addition of awareness of consequences for self and others and ascription of responsibility in Step 3, or with sexual motives for unprotected anal sex in Step 4. At this stage of the analysis, self-efficacy significantly contributed to the prediction of intention, whereas a marginally significant effect was found for subjective norms $(p<.10)$. When personal norms were entered in the final step of the analysis, a further $9 \%(p<.001)$ of variance was explained. In this model, the effect of personal norms was significant; however, the effects of subjective norms and self-efficacy dropped below significance, which suggested that the effects of subjective norms and self-efficacy were mediated through personal norms.

Testing this suggestion required that three conditions be met (see Baron \& Kenny, 1986). The first condition-that subjective norms and self-efficacy be related to intended condom use-was assessed in the above analysis (see Step 4, Table 4). The second condition requires that the mediator (i.e., personal norms) predict intended condom use and that subjective norms and self-efficacy have weaker effects when controlling for personal norms. This was also confirmed in the above analysis (see Step 5, Table 4). The third condition requires that subjective norms and self-efficacy significantly predict the mediator. To test this condition, personal norms were regressed on subjective norms and self-efficacy, while controlling for educational level and partner HIV status. Results revealed that subjective norms $(\mathrm{OR}=4.6, p<.001)$ and self-efficacy $(\mathrm{OR}=16.3, p<.001)$ were significantly related to personal norms. Thus, there was evidence that personal norms mediated the effects of self-efficacy on intended condom use. In addition, there was evidence that personal norms mediated the tentative influence of subjective norms.

\section{Casual sex partners}

Initially, a regression of condom use intention with casual sex partners on personal characteristics (age, education, antiviral treatment, and years knowing HIV-positive status) and partner variables (casual partners only versus steady partners as well) showed antiviral therapy to be the only statistically significant predictor. Therefore, only this variable was subsequently entered in Step 1 of the logistic regression analysis, yielding an explained variance of $6 \%$ (see Table 5). When the TPB variables were entered in the second step, a further $46 \%(p<.001)$ of the variance was explained. Attitudinal beliefs, subjective norms and self-efficacy significantly predicted intention, whereas a marginally significant effect was found for antiviral therapy. The entry of awareness of consequences for self and others and ascription of responsibility in Step 3 led to a further $8 \%(p<.001)$ of explained variance. Step 4 also accounted for a significant increase of variance explained with $3 \%(p<.01)$. In this step of the analysis, antiviral therapy, self-efficacy, ascription of responsibility and sexual motives significantly contributed to the prediction of intention, whereas a marginally significant effect was found for subjective norms $(p<.10)$. When personal norms were entered in the final step, a further $5 \%(p<.001)$ of variance was explained. As shown in Table 5, antiviral therapy and personal norms positively and sexual motives negatively predicted behavioral intention. Furthermore, the effects of subjective norms, self-efficacy and ascription of responsibility became non-significant, which suggested that these variables were mediated through personal norms.

To test this notion, we again assessed the three conditions specified by Baron and Kenny (1986). First, the analysis above revealed that self-efficacy and ascription of responsibility significantly predicted intended condom use, whereas a marginally significant effect was found for subjective norms (see Step 4, Table 5). Second, the above analysis showed that adding personal norms gave a significant regression coefficient for personal norms, and non-significant regression coefficients for subjective norms, self-efficacy, and ascription of responsibility (see Step 5, Table 5). Finally, in an analysis predicting personal norms while controlling for antiviral therapy, subjective norms (OR $=2.7, p<.05)$, selfefficacy $(\mathrm{OR}=3.0, p<.01)$, and ascription of responsibility $(\mathrm{OR}=10.5, p<.001)$ emerged as significant predictors. Taken together, these results provided evidence that personal norms were a mediator of the self-efficacy-intention and ascription of responsibility-intention relationships. In addition, evidence was found that personal norms mediated the tentative influence of subjective norms.

\section{Discussion}

The present study showed that the majority of HIV-positive MSM reported engaging in safer sexual behavior either though abstinence or consistent condom use for anal sex. Nonetheless, a high number of men who had had anal sex reported that they had not used condoms consistently with steady and casual sex partners. Results further indicated that HIV-positive MSM were more likely to engage in unprotected anal intercourse in the context of casual sex encounters than in steady sexual relationships (overall $34.1 \%$ and $24.7 \%$, respectively). This finding was consistent with 


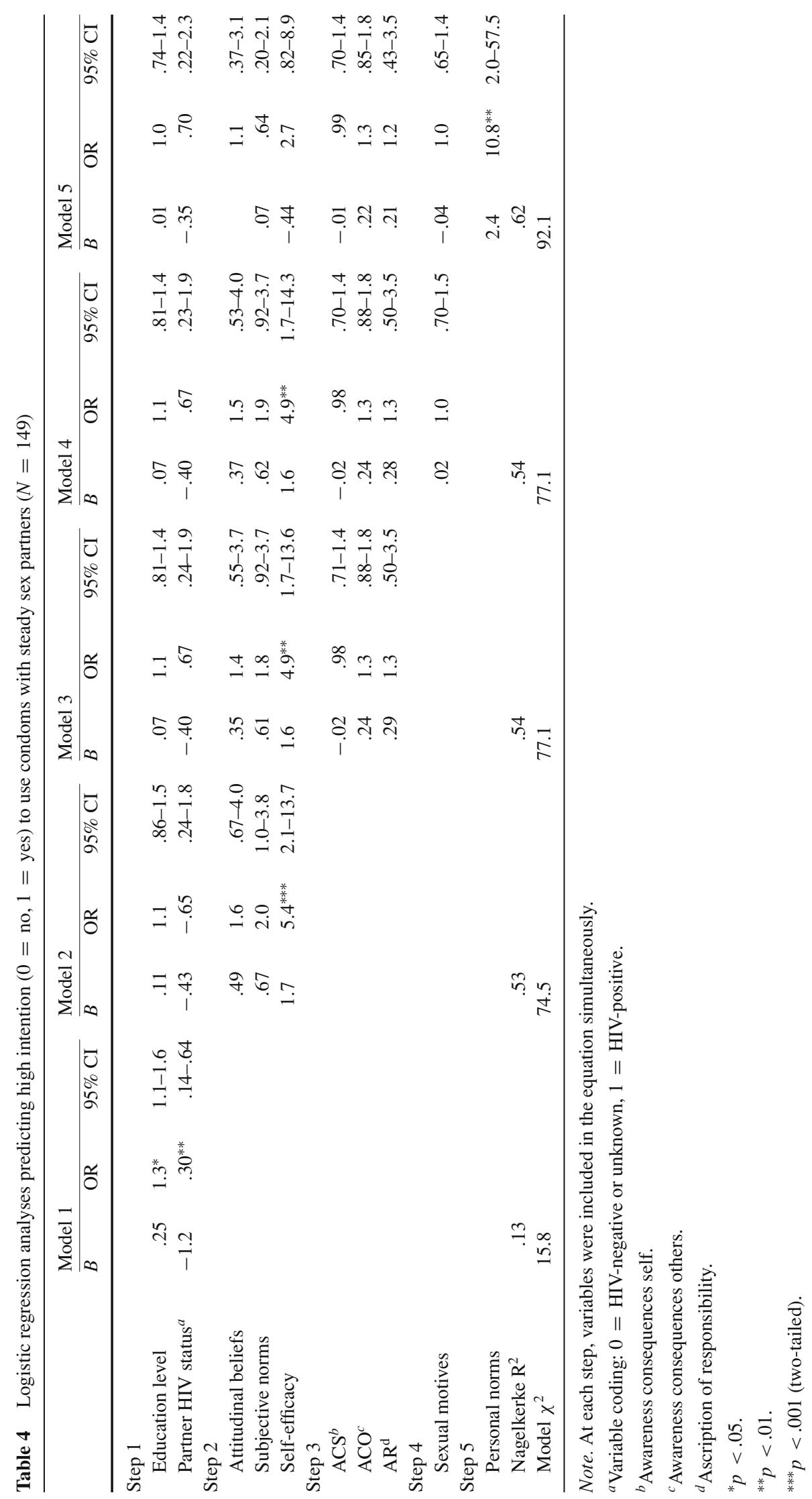




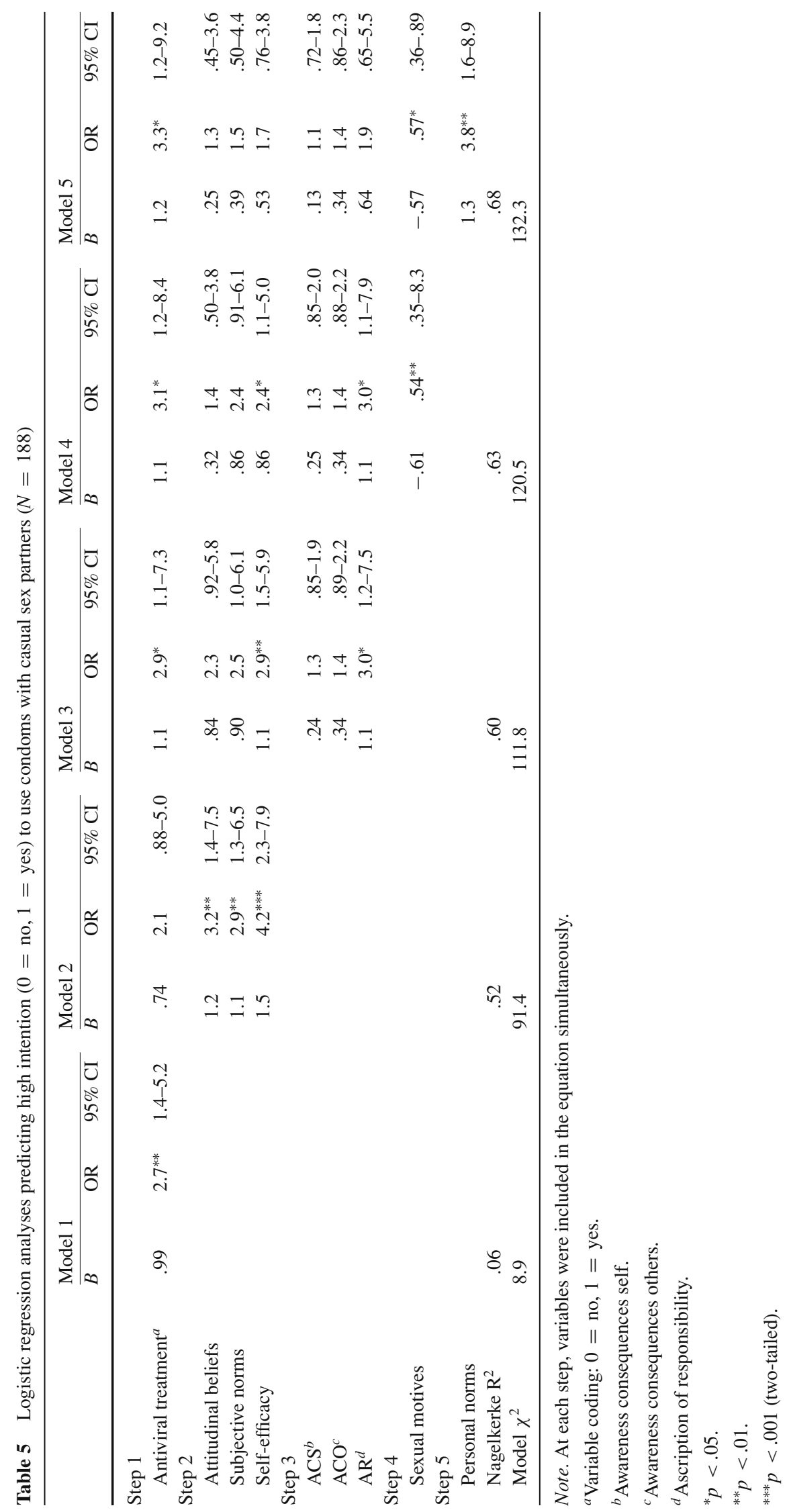


patterns of sexual risk behavior observed in other populations of HIV-positive MSM (cf. Crepaz \& Marks, 2002).

In this study, we tested a model of factors that influence intended condom use for anal sex with steady and casual sex partners. The results showed that, compared with the TPB (Ajzen, 1991), our proposed model of sexual decisionmaking led to a significant increase of explained variance from $53 \%$ to $62 \%$ for steady sex partners and from $52 \%$ to $68 \%$ for casual sex partners. Furthermore, evidence was obtained for the mediating role of personal norms on intended condom use with both steady and casual sex partners, suggesting that moral issues play an important role. However, the study also showed that sexual motives may undermine the influence of personal norms on intended condom use in the context of casual sex, with the likelihood of unprotected sexual intercourse. Taken together, the results revealed strong support for our model of sexual decision-making.

In this study, the finding that personal norms appeared to exert a strong direct effect on intention to use condoms with both steady and casual partners was consistent with results of earlier studies that suggest that safer sex in HIVpositive MSM is largely determined by moral concerns or feelings of personal responsibility (e.g., Godin et al., 1996). Moreover, this finding lends further indirect support to the proposition that condom use behavior among HIV-positive MSM is a form of prosocial behavior (e.g., Kok, 1999; Nimmons, 1998). For steady partners, personal norms were identified as the most proximal determinant of intended condom use, whereas an indirect effect was found for selfefficacy on intended condom use through personal norms. Furthermore, some evidence that personal norms mediate the tentative effect of subjective norms on intended condom use with steady sex partners was found. Similar results were found for intended condom use with casual sex partners. However, we also found an additional indirect effect of ascription of responsibility on intended condom use through personal norms. These findings are important because they underscore the need to take into account the role of social expectations, self-efficacy expectations, and attributions about responsibility for condom use in promoting feelings of moral obligation-a process that has not been identified in previous research on sexual risk behavior in HIV-positive MSM.

Furthermore, in the case of casual sex partners, condom use intention was not only directly related to personal norms, but was also negatively influenced by sexual motives for unprotected anal sex. Thus, the findings from this study suggest that the need to engage in unprotected anal sex for physical and emotional satisfaction may supercede the prosocial motivation for safer sex. The fact that sexual motives contributed toward explaining intended condom use in casual sex encounters but not in steady relationships does not imply that sexual motives are not important in the context of steady sex. More likely, there are some differences between steady and casual sex that encourage HIV-positive MSM to suppress sexual motives within the context of steady relationships but not within casual sex encounters. As discussed previously, a possible explanation may lie in the so-called affect-heuristic. In the context of casual sex, the benefits of unprotected sex may be more salient, thus resulting in a decreased assessment of risk. It is worth noting that the affect-heuristic is especially likely to color judgments under time pressure, which may play a more important role in the context of casual sex (Finucane et al., 2000). The "Coolidge effect" may also explain why sexual motives play a role in the casual sexual context, but not in steady sexual relationships. The Coolidge effect refers to enhanced sexual arousal that is felt when sexual stimuli and partners are novel (Gregoire, 1999). ${ }^{1}$ A final explanation may be the greater ambivalence that HIV-positive MSM experience in casual sex encounters as opposed to steady relationships. Greater ambivalence is likely to result in a reduction in both behavioral intention and actual behavior. In addition, people who experience ambivalence are more easily persuaded (Conner \& Armitage, 2000). It may be that pointing out the potential for casual sex partners to become steady partners in the future could increase the perceived benefits of safer sex, thus facilitating prosocial motivation to engage in protected sex. Indeed, the study by van Kesteren et al. (2005) suggests that such a mechanism exists. Further, the results of this study demonstrated that the use of antiviral therapy was associated with a greater intention to use condoms with casual sex partners. To date, inconclusive evidence exists regarding the association between the use of antiviral therapy and unprotected sex (for a meta-analysis, see Crepaz, Hart, \& Marks, 2004).

Some study considerations and limitations and implications for practice should be mentioned. First, as Ajzen and Fishbein (1970) held, it may be argued that the important role of personal norms as a predictor of intention can be attributed to a certain amount of overlap between the measures of personal norms and intention. In this study, high correlations were found between personal norms and intention. On theoretical grounds, however, it seems imperative to distinguish personal norms from intentions. As Manstead (2000) argued, holding the belief that something is morally "right" or "wrong" is not the same as the perceived likelihood of performing certain behaviors. Consequently, an individual may feel a personal obligation to act in a certain way, but intend to behave in a way that is contradictory to his personal norm because the personal or social advantages of acting inconsistently with his personal norm outweigh the personal or social advantages of acting consistently with the norm. Second, it should be noted that the data were crosssectional, which hampers conclusions about causality. Due

\footnotetext{
${ }^{1}$ We gratefully thank an anonymous reviewer for bringing up this suggestion.
} 
to the cross-sectional design, we did not specifically address the relationship between the psychosocial factors and behavior. It should be noted, however, that tentative support for our model was found in an additional analysis when intention was examined as a mediator of the personal norms-behavior relationship, both for steady and casual sex partners. Yet, longitudinal studies are needed to determine causative relationships between the measured constructs. A third limitation of the present study concerns the use of a single-item approach to measure awareness of consequences, as single-item measures are known to be less reliable. This issue merits attention in future research. Finally, the sample used in this study warrants some concern. More than $70 \%$ of those who received questionnaires did not respond. This raises the question as to whether these participants were predominantly more aware of the need to practice safer sex and, as such, are not a representative sample of Dutch HIV-positive MSM. On the other hand, Swanborn (2002) found that $30 \%$ is a common response rate for this type of research in the Netherlands. It is possible that the sensitivity of the subject and the fact that the participants suffer from a chronic disease may create barriers to participation. Moreover, substantial efforts were made to recruit HIV-positive MSM from throughout the Netherlands. Although this approach did not ensure that the sample was representative, it did enhance its diversity and therefore strengthens the external validity of the study results.

The findings reported in this study carry several implications for HIV-prevention efforts to promote safer sexual behavior among HIV-positive MSM. When addressing condom use behavior with steady and casual sex partners, it seems particularly crucial to enhance feelings of moral obligation to use condoms for anal sex. Feelings of moral obligation could be addressed by inducing HIV-positive MSM to reflect on their own personal risk and personal standards for safer sex (Kalichman, 1998). The findings of this study further suggest that desirable changes in subjective norms and self-efficacy expectations might lead to corresponding changes in personal norms and intentions (e.g., Deci \& Ryan, 2000; van Empelen, Kok, Jansen, \& Hoebe, 2001; van Empelen, Schaalma, Kok, \& Jansen, 2001). Therefore, preventive interventions should focus on helping HIV-positive MSM to cope with an unsupportive social environment and to encourage them to build the skills and confidence required for communicating and negotiating condom use. For the promotion of condom use with casual sex partners, personal norms may be further increased by urging HIV-positive MSM to accept responsibility for safer sexual behavior. Moreover, especially within casual sex encounters, it is imperative to help HIV-positive MSM to deal with feelings that may conflict with the goal of safer sex. Possible methods that can help HIV-positive MSM to identify and control high risk situations are, for example, action planning and coping planning (Sniehotta, Schwarzer, Scholz, \& Schüz, 2005). Action plans and coping plans are detailed plans of what a person needs to do when a specific situation occurs. When such situation arise, it is likely to function as a cue for the execution of those precise plans of implementation. Additionally, stimulating HIV-positive MSM to imagine how they would feel if they were in their sex partners shoes (i.e., perspective taking) may evoke a mixture of egoistic and altruistic motivation and, as such, lead to more protected sex (Batson, Early, \& Salvarani, 1997). That such an approach is feasible has been shown in a study by van Kesteren, Kok, Hospers, Schippers, and De Wildt (2006), in which the above-mentioned methods have been integrated in an intervention to promote sexual health in HIV-positive MSM.

Acknowledgements This study was funded by a grant from the Netherlands Organisation for Health, Research and Development (ZonMw, project no. 2100.0030). We would like to thank Marieke Kools for some helpful comments.

\section{References}

Ajzen, I. (1991). The theory of planned behavior. Organizational Behavior and Human Decision Processes, 50, 179-211.

Ajzen, I., \& Fishbein, M. (1970). The prediction of behavior from attitudinal and normative variables. Journal of Experimental Social Psychology, 6, 466-487.

Albarracin, D., Fishbein, M., Johnson, B. T., \& Muellerleile, P. A. (2001). Theories of reasoned action and planned behavior as models of condom use: A meta-analysis. Psychological Bulletin, 127, $142-161$.

Anon. (2002). Primary and secondary syphilis among men who have sex with men-New York City, 2001. Morbidity and Mortality Weekly Report, 451, 853-856.

Armitage, C. J., \& Conner, M. (2000). Attitudinal ambivalence: A test of three key hypotheses. Personality and Social Psychology Bulletin, $26,1421-1432$.

Bandura, A. (1986). Social foundations of thought and action: A social cognitive theory. Englewood Cliffs, NJ: Prentice-Hall.

Baron, R. M., \& Kenny, D. A. (1986). The moderator-mediator distinction in social psychological research: Conceptual, strategic, and statistical considerations. Journal of Personality and Social Psychology, 51, 1173-1182.

Batson, C. D., Early, S., \& Salvarani, G. (1997). Perspective taking: Imagining how another feels versus imagining how you would feel. Personality and Social Psychology Bulletin, 23, 751-758.

Colfax, G. N., Guzman, R., Wheeler, S., Mansergh, G., Marks, G., Rader, M., et al. (2004). Beliefs about HIV reinfection (superinfection) and sexual behavior among a diverse sample of HIVpositive men who have sex with men. Journal of Acquired Immune Deficiency Syndromes, 36, 990-992.

Cooper, M. L., Shapiro, C. M., \& Powers, A. M. (1998). Motivations for sex and risky sexual behavior among adolescents and young adults: A functional perspective. Journal of Personality and Social Psychology, 75, 1528-1558.

Crepaz, N., Hart, T. A., \& Marks, G. (2004). Highly active antiretroviral therapy and sexual risk behavior. Journal of the American Medical Association, 14, 224-236.

Crepaz, N., \& Marks, G. (2002). Towards an understanding of sexual behavior in people living with HIV: A review of social, psychological and medical findings. AIDS, 16, 135-149. 
Deci, E. L., \& Ryan, R. M. (2000). The 'what' and 'why' of goal pursuits: Human needs and the self-determination of behavior. Psychological Inquiry, 11, 227-268.

Flowers, P., Marriott, C., \& Hart, G. (2000). 'The bars, the bogs, and the bushes': The impact of locale on sexual cultures. Culture, Health and Sexuality, 2, 69-86.

Finucane, M. L., Alhakami, A., Slovic, P., \& Johnson, S. M. (2000). The affect heuristic in judgments of risks and benefits. Journal of Behavioral Decision Making, 13, 1-17.

Godin, G., \& Kok, G. (1996). The theory of planned behavior: A review of its applications to health-related behaviors. American Journal of Health Promotion, 11, 87-98.

Godin, G., Savard, J., Kok, G., Fortin, C., \& Boyer, R. (1996). HIV seropositive gay men: Understanding adoption of safe sexual practices. AIDS Education and Prevention, 8, 529-545.

Gregoire, A. (1999). ABC of sexual health. British Medical Journal, $318,245-247$.

Hogeweg, J., \& Hospers, H. J. (2000). Monitoronderzoek 2000. Maastricht: Maastricht University.

Kalichman, S. C. (1998). Preventing AIDS: A sourcebook for behavioral interventions. Mahwah, NJ: Lawrence Erlbaum Associates.

Kalichman, S. C. (2000). HIV transmission risk behaviors of men and women living with HIV-AIDS: Prevalence, predictors, and emerging clinical interventions. Clinical Psychology: Science and Practice, 7, 32-46.

Keogh, P., Weatherburn, P, \& Stephens, M. (1999). Relative safety: Risk and unprotected anal intercourse among gay men diagnosed with $H I V$. London: Sigma Research.

Kleinbaum, D. G., Kupper, L. L., Muller, K. E., \& Nizam, A. (1998). Applied regression analysis and other multivariable methods. Pacific Grove, CA: Duxbury Press.

Kok, G. (1999). Targeted prevention for people with HIV/AIDS: Feasible and desirable? Patient Education and Counseling, 36, 239246.

Manstead, S. R. (2000). The role of moral norm in the attitude-behavior relation. In D. J. Terry \& M. A. Hogg (Eds.), Attitudes, behavior and social context: The role of norms and group membership (pp. 11-30). Mahwah, NJ: Lawrence Erlbaum.

Macdonald, N., Dougan, S., McGarrigle, C. A., Baster, K., Rice, B. D., Evans, B. G., et al. (2004). Recent trends in diagnoses of HIV and other sexually transmitted infections in England and Wales among men who have sex with men. Sexually Transmitted Infections, 80, 492-497.

McConnell, J. J., Grant, R. M., \& Greenwood, G. (2002, July). Concerns about HIV superinfection and the sexual practices of seroconcordant couples [Abstract C10929]. Paper presented at the XIV International AIDS Conference, Barcelona.

Nelissen, R. M. A., Dijker, A. J. M., \& De Vries, N. K. (in press). Emotions and goals: Assessing relationships between values and emotions. Cognition \& Emotion.

Nimmons, D. (1998). In this together: The limits of prevention based on self-interest and the role of altruism in HIV safety. Journal of Psychology and Human Sexuality, 10, 75-87.

Nimmons, D., \& Folkman, S. (1999). Other-sensitive motivation for safer sex among gay men: expanding paradigms for HIV prevention. AIDS and Behavior, 3, 313-324.
Parker, D., West, R., Stradling, S., \& Manstead, A. S. R. (1995). Extending the theory of planned behavior: The role of personal norm. British Journal of Social Psychology, 34, 127-137.

Penner, L. A., Dovidio, J. F., Piliavin, J. A., \& Schroeder, D. A. (2005). Prosocial behavior: Multilevel perspectives. Annual Review of Psychology, 56, 365-392.

Rye, B. J., Fisher, W. A., \& Fisher, J. D. (2001). The theory of planned behavior and safer sex behaviors of gay men. AIDS and Behavior, $5,307-317$.

Schwartz, S. H. (1973). Normative explanations of helping behavior: A critique, proposal, and empirical test. Journal of Experimental Social Psychology, 9, 349-364.

Schwartz, S. H. (1977). Normative influences on altruism. In L. Berkowitz (Ed.), Advances in experimental social psychology (Vol. 10, pp. 221-279). New York: Academic Press.

Schwartz, S. H., \& Howard, J. A. (1981). A normative decision-making model of altruism. In J. P. Rushton \& R. M. Sorrentino (Eds.), Altruism and helping behavior: Theories and research (pp. 327353). New York: Academic Press.

Sheeran, P., Abraham, C., \& Orbell, S. (1999). Psychosocial correlates of heterosexual condom use: A meta-analysis. Psychological Bulletin, 125, 90-132.

Sniehotta, F. F., Schwarzer, R., Scholz, U., \& Schüz, B. (2005). Action planning and coping planning for long-term lifestyle change: Theory and assessment. European Journal of Social Psychology, $35,565-576$.

Swanborn, P. G. (2002). Basisboek sociaal onderzoek. Meppel: Boom.

van de Laar, M. J. W., \& Op de Coul, E. L. M. (2004). HIV and sexually transmitted infections in the Netherlands in 2003. An update: November 2004. Bilthoven: RIVM.

van Empelen, P., Kok, G., Jansen, M. W. J., \& Hoebe C. J. P. A. (2001). The additional value of anticipated regret and psychopathology in explaining intended condom use among drug users. AIDS Care, 13, 309-318.

van Empelen, P., Schaalma, H. P., Kok, G., \& Jansen, M. W. J. (2001). Predicting condom use with casual and steady sex partners among drug users. Health Education Research, 16, 293-305.

van Kesteren, N. M. C., Hospers, H. J., Kok, G., \& Van Empelen, P. (2005). Sexuality and sexual risk behavior in HIV-positive men who have sex with men. Qualitative Health Research, 15, 145168.

van Kesteren, N. M. C., Kok, G., Hospers, H. J., Schippers, J., \& de Wildt, W. (2006). Systematic development of a self-help and motivational enhancement intervention to promote sexual health in HIV-positive men who have sex with men. AIDS Patient Care and STDs, 20, 858-875.

Weinhardt, L. S., Carey, M. P., Johnson, B. T., \& Bickman, N. L. (1999). Effects of HIV counseling and testing on sexual risk behavior: A meta-analytic review of published research, 1985-1997. Americal Journal of Public Health, 89, 1397-1405.

Wolitski, R. J., Bailey, C. J., O’Leary, A., Gómez, C. A., \& Parsons, J. T. (2003). Self-perceived responsibility of HIV-seropositive men who have sex with men for preventing HIV transmission. AIDS and Behavior, 7, 363-372. 